\title{
A crise socioambiental e a atuação de ONGs ambientalistas no campo educacional
}

\author{
Jéssica do Nascimento Rodrigues \\ Universidade Federal Fluminense \\ Carlos Frederico Bernardo Loureiro \\ Universidade Federal do Rio de Janeiro
}

\section{Resumo}

Sob a perspectiva de "fim da história" e naturalização do modo de produção capitalista, a crise socioambiental é incorporada ao discurso de mercado, tornandose estratégica para a manutenção do capitalismo. Essa "arte do contornamento", com "roupagem verde", conserva as relações de exploração do trabalhador e da natureza. Não obstante, surgem mecanismos de luta, entre eles a educação ambiental, vista pelo prisma crítico-transformador. De outra parte, instituições de assessoramento aos movimentos sociais, como as ONGs, invadem o campo educacional, sob o pretexto de fazer aquilo que o Estado não faz e reforçando uma lógica de Estado Gerencial. Objetiva-se, assim, evidenciar tais questões e a urgência da pesquisa acerca desse debate para a educação ambiental.

Palavras-chave: Crise socioambiental. Educação ambiental. Organizações Não Governamentais. 


\section{The environmental crisis and the work of environmental NGOs in the field of education}

Under a perspective of the "end of history" and of naturalization of capitalist production, the socio-environmental crisis is incorporated into the market discourse and becomes strategic for the maintenance of capitalism. This "art of circumvention", with "green clothing" conserves exploitation relationships with workers and with nature. Notwithstanding, mechanims of struggle appear, among them environmental education, as seen through a critical-transforming prism. On the other hand, institutions which are working as advisors to social movements, such as NGOs, invade the field of education, under the guise of doing that what the state shoud do, reiforcing the logic of the Manatement State. Therefore, the goal os this paper is to highlight these issues and stress the need for research on this debate for environmental education.

Keywords: Socio-environmental crisis. Environmental education. Non-governmental organizations.

\section{La crisis socioambiental y la actuación de ONGs ambientalistas en el campo educacional}

Desde una perspectiva ideológica del "fin de la historia" y la naturalización del modo de producción capitalista, la crisis socio-ambiental es incorporada al discurso de mercado y se convierte en un medio estratégico para el mantenimiento del capitalismo. Este "arte de la elusión," con una "vestimenta verde", mantiene relaciones de explotación de los trabajadores y la naturaleza. Sin embargo, hay mecanismos de defensa, que incluye la educación ambiental, considerada a través del prisma crítico-transformador. De otra parte, instituciones de asesoramiento a los movimientos sociales como las ONG, invaden el campo de la educación, bajo el pretexto de hacer lo que el Estado no hace y reforzando la lógica de la Administración del Estado. El objetivo de ese articulo es poner de relieve estos temas y subrayar la urgencia de investigaciones sobre este debate para la educación ambiental

Palabras clave: Socio-ambientales crisis. La educación ambiental. Las organizaciones no gubernamentales. 


\title{
Para Introduzir o Debate
}

\begin{abstract}
Árvore em fogo
Na tênue névoa vermelha da noite / Víamos as chamas, rubras, oblíquas Batendo em ondas contra o céu escuro / No campo em morna quietude Crepitando / Queimava uma árvore.
\end{abstract} Para cima estendiam-se os ramos, de medo estarrecidos Negros, rodeados de centelhas / De chuva vermelha Através da névoa rebentava o fogo / Apavorantes dançavam as folhas secas Selvagens, jubilantes, para cair como cinzas / Zombando, em volta do velho tronco. Mas tranquila, iluminando forte a noite / Como um gigante cansado à beira da morte Nobre, porém, em sua miséria / Erguia-se a árvore em fogo. E subitamente estira os ramos negros, rijos / A chama púrpura a percorre inteira Por um instante fica erguida contra o céu escuro. E então, rodeada de centelhas / Desaba. (Bertold Brecht, 2000, p. 9).

Como o poeta, em sua inspiração e intimidade com as palavras, pode transformar aquilo que parece simples ou corriqueiro em algo tão belo? Como pode ser belo aquilo que, em verdade, não o é? Como pode ser verdade que o que não é belo se naturalize e se banalize? Bertold Brecht (1898-1956), junto ao movimento expressionista ao qual se aliou, escreveu seus poemas e suas peças vivendo a "Alemanha de Hitler", muitas vezes para alertar e, mormente, para buscar transformar aquilo que choca, aquilo que incomoda, a árvore a desabar percorrida pelo fogo, aquilo que causa, em certa medida, angústia, inquietação.

E é a partir desse desafio, evidenciando as atrocidades a que o ambiente vem sendo submetido - atrocidades cotidianizadas e relativas ao modo como socialmente estamos organizados -, que este texto foi produzido. Intenciona-se, portanto, evidenciar a crise socioambiental hodierna que, intensificada nesta Terceira Revolução Técnico-Científica, ajusta-se às (re)configurações do modo de produção capitalista. Ademais, é também objetivo discutir que, com o advento da educação ambiental a partir da década de 1970, campo educacional importante para se pensar a superação deste momento de barbárie, contraditoriamente novos mecanismos de "contornamento" para a manutenção do sistema se explicitam. Entre as diversificadas instituições aliadas a esse quadro, focar-se-ão, neste artigo, as Organizações NãoGovernamentais (ONGs) como fortes agentes sociais atuantes tanto no campo educacional quanto no campo ambiental, cuja institucionalidade se configurou desde a década de 1980 como protagonista na relação sociedade civil e Estado. 
Vistos inicialmente como agentes democratizantes e vinculados às lutas populares, com a reorganização do Estado e o avanço do processo de precarização do trabalho, as ONGs acabaram por assumir função fortemente vinculada à parceria com setores empresariais e governamentais, atuando por meio da execução de projetos, em uma lógica pragmática de resolução de problemas, que tende a suprimir os conflitos sociais e a esvaziar as políticas públicas (Dagnino, 2005). Para respaldar a discussão aqui proposta, destarte, far-se-á uma contextualização sintética da crise socioambiental em que se enquadra a sociedade atual, consoante alguns referenciais contemporâneos e serão feitos alguns apontamentos acerca das imbricações entre Organizações Não-Governamentais e a educação ambiental nesse contexto. Optouse por uma escrita em texto corrido, sem subdivisões, como estratégia estilística que dá sentido ao entrelaçamento desses temas.

\section{Crise, Organizações Não Governamentais Ambientalistas e Educação Ambiental}

A crise socioambiental é notória e não raramente é naturalizada como irresoluta e imersa numa crise de caráter permanente. A crise hodierna "insuperável", advinda da modernização do consumo e fruto do projeto de expansão do capital monopolista e financeiro - em que os padrões civilizatórios funcionam como início e fim de si mesmos -, é inegavelmente estado de exceção permanente, na violência estatal e empresarial sobre os homens e sobre a natureza (Mèszaros, 2002). A crise, da socioambiental à civilizatória, em cujo cerne se dá a crise econômica, ética, moral, política, em uma gama de fatores interconexos, advém de uma história de injustiça, desigualdade e exploração. A natureza do capital e a produção capitalista mundializados, segundo Chesnais (2009), são as raízes dessa problemática e merecem um exame mais minucioso, tendo em vista que suas contradições nos querem informar, a todo tempo, a propensa finitude do padrão societário vigente.

Nesse contexto, em nosso dia a dia, da mídia à escola, ouvem-se e (re)produzem-se informações acerca dessa problemática. Reconhece-se a gravidade da crise climática, por exemplo, entretanto desvinculada da crise maior. No cotidiano, banalizam-se a degradação ambiental, a violência, a pobreza, e, diante dessa banalização generalizada, o modo de produção capitalista se reproduz e amplia a acumulação de riquezas, criando “seres adaptados às formas germinais da barbárie" (Menegat, 2006).

Em outras palavras, há a "aceitação das manifestações positivas da barbárie como naturais" (Menegat, 2006, p. 58). Outrossim, adverte Arantes (2004a), quando comenta o efeito da brasilianização sobre os ditos países desenvolvidos, "na hora histórica em 
que o país do futuro parece não ter mais futuro algum, somos apontados, para mal ou para bem, como futuro do mundo" (Arantes, 2004a, p. 30).

Em meio a tais contradições entre um desenvolvimento produtor de riquezas e a coisificação da vida, o avanço da Terceira Revolução Industrial ou da Revolução Técnico-Científica ganha proporções avassaladoras/destruidoras, o que Oliveira (2007) chama de "contra-revolução de nosso tempo", somando-se à questão socioambiental como uma aliada, uma vez que "a destruição da natureza em grande escala não é fruto necessariamente de uma concepção da ciência, mas do uso desta feito pelo capital" (Menegat, 2006, p. 59). Ainda, consoante Santos (2007), vivemos a desordem como se fosse a ordem, e a exceção como normalidade, e nessa linha diáfana se podem entrever os avanços técnico-científicos em sua positivação pari passu à degradação ambiental, legal/ilegal, necessária para tanto.

0 que é legal, para muitos, é o fato de os índios tembé-ténêtéhar da terra indígena Alto Rio Guamá, no noroeste do Pará, assinarem contrato de crédito de carbono para preservação florestal com a empresa americana C-Trade (Melo, 2009). No caso, tal acordo evitaria que os tembé-ténêtéhar vendessem madeira ilegal para seu sustento, já que receberiam $85 \%$ das vendas do crédito de carbono no mercado internacional. De encontro a isso, Fernandes (1995, p. 147) infere: "0 comando fica no exterior, nas matrizes das corporações gigantes, nas organizações financeiras, culturais e políticas das nações hegemônicas e nas mãos de suas elites políticas, dirigentes dos estados imperialistas". Tanto e como quase sempre, fala-se "amém" ao domínio dos grupos que detêm o capital, e isto não deixa de envolver questões ideológicas, políticas e culturais profundamente arraigadas no imaginário e na economia brasileiros. Ainda partindo desse exemplo, pode-se entender que "não se trata propriamente de ilegalidades (novas e velhas), mas de uma crescente e ampliada zona de indiferenciação, entre o lícito e o ilícito, entre o direito e o não direito, entre o público e o privado, entre a norma e a exceção, que passa por toda a trama da vida social" (Telles, 2007, p. 203).

Os padrões civilizacionais atuais, ademais, numa "dialética da malandragem"1, mantêm a venda de animais silvestres nas feiras livres sob os narizes das autoridades e da sociedade em geral - que os compra e os exibe e, sabendo da ilegalidade de sua comercialização, toma-a como bobagem. Para Telles (2007, p. 216), “Indivíduos e suas famílias transitam nessas tênues fronteiras do legal e do ilegal, sabem muito bem lidar com os códigos de ambos os lados e sabem também, ou, sobretudo, lidar com as regras que são construídas para "sobreviver na adversidade".

1. Dialética da malandragem, segundo Arantes (2004a, p. 74), é “[...] o fio malandro da ordem e da desordem na urbanização à brasileira. [...] a legislação tanto pode ser aplicada ou não ser; ora vale a informalidade clientelista, ora as leis de mercado". 
É a "arte do contornamento" que se encontra arraigada no cotidiano e, principalmente, positivada nos clichês do "jogo de cintura". À guisa disso, as construções de hidrelétricas, sob a égide do velho discurso desenvolvimentista e à mercê do progresso, persistem em outra realidade distante dos centros urbanos, impactando o ambiente e até acometendo suicídios nas comunidades ribeirinhas/ indígenas perdidas em uma realidade diferente daquela com a qual viviam (Porto e Pacheco, 2009). Geração de energia para grandes indústrias e geração de desemprego, de morte, de desamparo, do outro lado de cá. 0 importante é assumir uma "cara moderna, democrática e pedagógica, ou seja, participativa" (Paoli, 2007, p. 236). Como aconteceu com dois pescadores (desempregados afinal e não satisfeitos com a situação em que se encontravam): após a instalação de uma dada empresa em Santa Cruz/RJ e "remoção" dos pescadores, estes foram mortos (Tinoco, 2011). Assim, ainda para Paoli (2007, p. 236), “um pressuposto impositivo, portanto, o modelo econômico atual obriga a reivindicação e o diálogo a entrarem nos estreitos espaços daquilo que é permitido acontecer".

Nas palavras de Fernandes (1995, p. 155), "como se desenrola nos núcleos imperiais, a natureza e as consequências do processo global devem ficar fora do campo de visibilidade do senso comum. A neutralidade ideológica emerge como uma imposição primordial." E no afã das ideologias, em seu sentido mais perverso, a pobreza vincula-se à degradação cuja simbologia se pode enxergar na construção de um muro no morro Santa Marta, favela do Rio de Janeiro, que separa a comunidade do resto de Mata Atlântica. Despolitiza-se o problema socioambiental e culpa-se a comunidade já marginalizada em sua sobrevivência. Também não se pode deixar de destacar as influências midiáticas para o discurso comportamentalista/individualista de que "cada um deve fazer a sua parte". Para falar em mídia, Arantes contesta-a:

Nesse mesmo passo, uma boa mídia se encarregará - como é de natureza do veículo de despolitizar a desigualdade, agora sim, assustadora. Numa cidade convenientemente repartida entre bárbaros e civilizados, as divisões acabam se resumindo a oposições onódinas entre violência e convivência, solidariedade e egoísmo, etc. (Arantes, 2004a, p. 45).

Em suma, despolitiza-se a desigualdade, despolitiza-se a questão ambiental. Destarte, na flexibilização à brasileira do mundo, caractere da brasilianização a que o Brasil se encontra na vanguarda (Arantes, 2004a) -, pode ser claramente reconhecida a crise socioambiental. Demarcam-se pequenas áreas para preservação - numa vertente ecológico-preservacionista herdeira ainda de uma visão cartesiana - no contraponto da destruição exacerbada nos quatro cantos do mundo. Os "homens precários" batalham na informalidade da extração de madeiras enquanto as 
informações midiáticas isentam a overclass da culpa, a qual aponta o dedo para o rosto do indivíduo que joga o lixo no chão.

$E$ é nesse contexto que a educação ganha o tom remediador dos males socioambientais em cuja nova pedagogia da hegemonia busca inspiração. E é essa a "nova" pedagogia mantenedora do capital, uma vez que se dá na produção e na reprodução material desta sociedade de classes. Tal pedagogia se apropria de um discurso aparentemente revolucionário, adequando-o à manutenção/conservação/ perpetuação. Como comentam Lima e Martins:

Assim, temas antigos, como "cidadania", "igualdade”, "participação", "democracia”, e novos, como "empreendedorismo", "voluntariado", "responsabilidade", dentre tantos outros, são tratados sob uma abordagem pedagógica que os distancia do conflitivo e antagônico processo de construção social que os define. (Lima e Martins, 2005, p. 65).

As relações políticas são relações pedagógicas. Assim sendo, a pedagogia da hegemonia se dá na produção e reprodução material de uma sociedade de classes a fim de mantê-la, e essas relações de aprendizagem em favor do capital fazem dessa pedagogia algo sempre renovado. 0 discurso sobre a participação, a democratização e a cidadania estão, nesse contexto, presentes em discursos, programas e projetos, tomam dimensões internacionais e compõem as exigências de agentes financeiros internacionais (Uema, 2006). Incentiva-se a coesão social, o empreendedorismo social e a ação voluntária (Lima e Martins, 2005).

Apesar de haver o reconhecimento da existência dessa nova pedagogia da hegemonia, em sua profunda ideia de manutenção da ordem por meio das ideologias do consensual - por meio de ideologias que transformam as necessidades do trabalhador nas mesmas da classe dominante -, é na radicalização da democracia no capitalismo que é possível a disputa de forças políticas distintas. Verbaliza-se a democracia, criando a ilusão da sua concretude, mas não há a sua efetiva realização.

Para Arantes (2004b, p. 166), “Não obstante, fica assim mesmo a impressão de um amistoso compadrio vocabular, como se ONGs e governo formassem um sistema de vasos comunicantes, pelos quais circula o mesmo léxico dos Direitos, da Cidadania, da Esfera pública, da Sociedade Civil etc". Em outras palavras, fica a impressão de uma relação harmoniosa, sem conflitos, e utiliza-se um vocabulário "unívoco" para procriar tal relação. E prossegue o autor:

Quando o ativista de uma ONG anti-establishment se envolve numa disputa política em torno do sentido das palavras 'direitos', 'cidadania', 'espaço público', 'equidade 
social' etc, é porque se ressente da pouca ou quase nenhuma nitidez - para não falar em promiscuidade - na demarcação dos campos em conflito. (Arantes, 2004b, p. 183).

É nesse contexto que se gestou a Política Nacional de Educação Ambiental (PNEA, 1999) e que, em 2009, comemoraram-se, nas searas da educação ambiental, seus dez anos de vida com bastante vigor. Essa Política vem servindo, até os dias de hoje, de base para a construção das respectivas políticas, nos âmbitos estaduais e municipais, e vêm também se constituindo no embate hegemônico: a educação ambiental conservadora - que malandramente se esgueira das mudanças substanciais para germinar em vertentes romantizadas, comportamentalistas, bancárias, ecológicopreservacionistas, enfim - e a educação ambiental crítico-transformadora ${ }^{2}$ - baseada na resistência ao que está posto e na contra-hegemonia, na luta pela superação do padrão civilizacional hodierno (Rodrigues, 2010).

Legitimadas também pela PNEA, muitas ONGs, influenciadas pelo Banco Mundial na perspectiva da Terceira Via, emergiram com o intuito de substituir o Estado nas ações socioambientais. No entanto, autores como Arruda (1996), Camba (2009) e Gohn (2008) veem em algumas dessas entidades uma postura crítica em relação às instituições multilaterais. 0 Banco Mundial, de fato, vem atuando no sentido de sustentação da sociedade capitalista, seja financiando o Estado nas décadas de 40, 50 e 60, seja nos indicativos para a desregulamentação geral contra os trabalhadores, por exemplo, com o aumento do tempo de contribuição e da idade para a aposentadoria.

Entretanto, Arruda (1996), na época, enxergando possibilidades positivas nas ONGs, afirma que estas questionam as ações do Banco Mundial. Todavia, o que se percebe hoje é que as ONGs têm funcionado como um instrumento de privatização do Estado, muitas vezes recebendo recursos sem fiscalização e sem terem sido "capazes" de uma atuação concreta contra as orientações do referido Banco. Em resumo, nesta conjuntura de hegemonia da perspectiva do Estado subserviente ao capital, as políticas educativas se enquadram nessa lógica do mercado. 0 Banco Mundial dita "regras", influenciado pelos Estados Unidos, sobretudo, e as políticas educativas devem segui-las a fim de se adequarem aos padrões hegemônicos. Logo, a escola gera capital humano para atender o mercado, e, ao mesmo tempo, - capital modifica as estruturas pedagógicas quando se reconfigura para manter a sua dominação. Assim, existem, segundo Lima e Martins (2005), duas noções para a sustentação do capital: o capital humano (todos são capitalistas, ou seja, não existem

2. Para Rodrigues (2010), houve esvaziamento do "crítico" no sentido de negação, com apelo ético. Ao apontar a educação ambiental como crítico-transformadora, delineia-se um campo em tensão. Aqui, "crítico" ganha contorno de confronto com o padrão societário atual como tentativa de implementar uma sociedade alternativa. 
classes sociais: uns possuem os meios de produção e outros, o capital humanol e o capital social (articulação dos grupos buscando a solução de problemas imediatos).

$\mathrm{Na}$ busca do estabelecimento do consenso, lança-se mão de artimanhas que invadem todos os campos da vida social, entre eles o campo educacional. Os discursos hegemônicos prestam-se à tentativa de abafar os discursos contracorrentes e muitos temas, como o da educação ambiental, emergem nesse embate atravessados por ambiguidades, por ambivalências e, sobretudo, por "visões ideológicas de mundo" (Löwy, 1988). 0 campo educacional inclui a educação ambiental, não obstante seja campo de disputa, como um mecanismo propenso a mudanças na realidade posta. Dessa forma, vê-se, por exemplo, na formação de educadores, sobretudo de educadores ambientais, um caminho para o desenvolvimento de uma educação diferenciada (Rodrigues, 2010).

Todavia, cabe questionar de que educação ambiental e de que formação de educadores se fala. As práticas sociais - e nelas os discursos - têm a dimensão ideológica, em sua hegemonia de sentido, refletindo/refratando a realidade como instrumento sobremaneira perigoso por arrematar-se à ideia de naturalização/ banalização/perpetuação deste modo de produção material da vida. Para a sua manutenção/conservação, instituições são criadas, reformuladas, anuladas e, nesse caminho, as Organizações Não Governamentais - pouco estudadas, quase indescritíveis, deveras legitimadas - entram em campos vários, intervindo na educação, na educação ambiental e na formação de educadores sob o pretexto da mediação das políticas públicas. Assumindo um papel de terceiro setor ou de "sociedade civil" organizada, as ONGs se preocupam com as microesferas em detrimento das macroesferas, sendo estas deixadas para o Estado (Coutinho, 2003).

De acordo com Montaño (2008), as ONGs, nos anos 60 e 70, já foram importantes atores coadjuvantes, lado a lado, dos movimentos sociais. Com o advento do neoliberalismo, a situação toma outro rumo e tais organizações passam a compor parcerias com o Estado e com o capital. Assim como aconteceu com o termo "luta de classes" e com o termo "exploração", houve uma mudança na linguagem e, com isso, participação social se tornou o novo "filão" do neoliberalismo atual. Consoante Montaño (2008, p. 43), “a representatividade dos interesses da classe trabalhadora e dos setores subalternos foram substituídos pelas ONGs, com suas novas determinações e seu novo papel social". Ao desmobilizar os movimentos sociais e cumprir importante papel ideológico, as ONGs ambientalistas, que conquistam mais e mais espaços - e financiamento -, merecem mais estudos - por fora delas - que procurem apontar, de uma vez por todas, a que se prestam. Vale ressaltar que, segundo Uema (2006), no ano de 2000, as agências internacionais estavam em primeiro lugar no financiamento das ONGs e, em segundo, estavam os órgãos governamentais federais, estaduais e municipais. Coutinho (2003) não descarta as 
Igrejas e afirma que, tendo a viabilidade na capacidade de angariar fundos, as ONGs não conseguem atuar de forma mais radical.

Complexas, contraditórias e diversificadas, as ONGs ganham identidade no ofuscamento de suas funções, as quais, costuradas às necessidades de manutenção do modo de produção capitalista, passam distante de pensar seu rompimento. Estudadas de dentro delas, nas suas próprias vozes, merecem um olhar cuidadoso desatrelado de sua lógica, mas que se firme com o compromisso crítico acerca desse tipo de instituição. De acordo com Montaño (2008), as ONGs têm assumido a representação da "sociedade civil" nos conselhos, no espaço público e nos jornais, transformandose em portadoras de representatividade da classe trabalhadora. Trata-se de um novo conceito de participação (como dito) compondo-se em um contexto de crise estrutural.

Abraçando a causa da "resolução" das problemáticas sociais, sob o discurso do "fazer aquilo que o Estado não faz", as ONGs investem forte no interesse pelos campos educacional e ambiental. Por exemplo, de acordo com Camba (2009, p. 31), $40 \%$ das ONGs no Brasil são ecológicas e, "[...] sem a sua contribuição, a educação ambiental no país não teria avançado tanto [...]", entretanto não fica claro de que educação ambiental fala a autora. Gohn (2008) concorda que o papel e a natureza das ONGs são indeterminados em virtude da infinidade e diversidade dessas entidades; dessa maneira, não se pode contar com um cadastro fiel à realidade. Além disso, não há clareza quanto a seus projetos políticos, a seus objetivos e a seus mecanismos de sustentação econômica, embora haja seu crescimento devido à crise mundial do setor público, ao fracasso das políticas públicas tradicionais e ao apelo à mídia (Uema, 2006).

Montaño (2001) lembra que as entidades independentes, filantrópicas e voluntaristas - como é o caso das ONGs - têm atendido à demanda social emergencial como atividade curativa e assistencialista. Cria-se uma dependência crônica entre os atendidos e as entidades atendentes a partir de um atendimento precário, calandose as vozes desconformes.

Concomitante a esse turbilhão das ONGs na década de 1970, a educação ambiental - entendida aqui como um braço da educação que, quando crítica, pressupõe a questão ambiental - emerge como um mecanismo importante no enfrentamento da crise socioambiental. E uma das questões centrais neste debate é que a referida crise, difundida a torto e a direito, não vem sendo relacionada criticamente com o padrão societário vigente. É nessa "opacidade" da crise que se mantém a igual opacidade da educação ambiental conservadora, que é hegemônica nas escolas (Loureiro, 2005).

Ao contrário disso, a educação ambiental crítico-transformadora, movimentandose contra-hegemonicamente, concebe a necessidade e a urgência de superação desta sociedade, pela emancipação humana, pelo entendimento de que uma sociedade mais justa é possível, pelo entendimento de que o percurso histórico é dialético e, portanto, 
mutável. É relevante, por conseguinte, perscrutar a que se prestam - a partir de quais discursos e de quais práticas - as ONGs ambientalistas ao apropriarem-se da educação ambiental e da formação de educadores. Nesse contexto de neoliberalismo de "cara nova", ou de nova socialdemocracia, ou de Terceira Via, que se remete à nova "implosão semântica do léxico" (Arantes, 2004b). 0 discurso que inclui a novidade - o novo cidadão, o novo trabalhador, as novas organizações, uma nova educação - "maquia o monstro", reconfigurando/renomeando, numa "nova pedagogia da hegemonia" (Melo, 2005), um padrão de sociedade em cujo âmago perdura a acumulação de capital e a exploração. Por trás disso, as ONGs ambientalistas parecem predominantemente coniventes no aperfeiçoamento das novas estratégias do capital na calada do conflito, e, unindo-se à educação, revigora-se a alienação. É indispensável investigar, numa época em que o indeterminado vigora e em que "qualquer coisa quer dizer qualquer coisa, significado perdeu o significado" (Arantes, 2004a, p. 179), o papel das ONGs ambientalistas e sua atuação no campo educacional. Consoante Uema (2006, p. 79), “as ONGs são todas as organizações que não pertencem à esfera estatal, que não estão vinculadas ao governo, que não têm fins lucrativos. A busca da identidade pela negação parece ser uma constante." A definição "sem-fins-lucrativos" pode representar uma senha privilegiada para a entrada no mundo dos negócios (Arantes, 2004b). Nesse mesmo viés, Coutinho (2003) caracteriza as ONGs como "anti-governo", "anti-burocracia" ou "antilucro". A indeterminação dessas entidades se soma à "arte do contornamento" aderida pela educação. E a educação ambiental, não obstante não seja unívoca, finca seus pés predominantemente no conservadorismo, limitando-se a informar a problemática socioambiental, a responsabilizar os indivíduos isoladamente (Guimarães, 2004) ou a priorizar a reciclagem em detrimento da redução e da reutilização (Layrargues, 2005).

Cabe ressaltar que, colocadas ora como "sociedade civil" organizada, ora como "terceiro setor", as ONGs apontam a ineficácia do Estado enquanto remediador do mal da exclusão dos trabalhadores ou promotor de justiça socioambiental. No entanto, para Coutinho (2003), "0 "terceiro setor" deve ser colocado no seu devido lugar. Ou seja, ele cumpre um papel ideológico importante na implementação das políticas neoliberais e está em sintonia com o processo de reestruturação do capital pós 70: de flexibilização dos mercados nacional e internacional, das relações de trabalho, da produção, do investimento financeiro", além de "chamar para a "sociedade civil" a responsabilidade para a resolução dos problemas sociais". Entre os caminhos percorridos pelo terceiro setor sustentado pelo projeto neoliberal, Montaño (2001) cita justamente a desresponsabilização do Estado na intervenção social, voltando-se as respostas às sequelas da questão social às organizações da sociedade civil; ou ainda a responsabilidade do conjunto da sociedade volta-se para a autorresponsabilidade dos próprios necessitados. 
Ademais, de acordo com Gohn (2008, p. 91), “cursos, seminários, capacitações e até treinamentos passaram a ser rotinas de pacotes de serviços oferecidos e vendidos pelas ONGs", respondendo à sua nova conjuntura econômica e aos critérios dos financiadores internacionais, e, dessa maneira, a educação torna-se mais um campo de atuação dessas entidades. 0 financiamento das ONGs, segundo Petras (1999), visa exatamente ao oferecimento de projetos de autoajuda (afinal são uma fonte de empregos), de qualificação/treinamento profissional e de educação popular (para dar apenas alguns exemplos). As ONGs, outrossim, em virtude de sua não rigidez, de sua indeterminação, mudam fácil e rapidamente, em congruência com as mudanças conjunturais políticas.

Ainda segundo Gohn (2008), os “ongueiros" têm uma gramática própria, cuja oralidade predomina, incorporando elementos que tornam as ONGs "modernas", utilizando muitas vezes discursos carregados de ideologias que vão ao encontro da “[...] visão cidadã de mundo - rodeada de 'parceiros' e de 'interlocutores'” (Arantes, 2004b, p. 167]. Daí que “[...] esse mundo de ponta-cabeça não obstante é palco de batalhas de interpretação [...]" (Arantes, 2004b, p. 178). Nessa batalha, parece que as próprias ONGs tornam-se campo de disputa. Gohn (2008) diferencia as ONGs ditas cidadãs e as entidades do terceiro setor. Nos termos da autora, as ONGs cidadãs “[...] se fundam numa cultura política que prioriza, nos processos de mudanças e transformações sociais, a conquista, a defesa ou a ampliação de diferentes tipos de direitos da população como um todo e a emancipação sociopolítica e econômica de amplas camadas da população [...]" (Gohn, 2008, p. 92). As entidades do terceiro setor, para Gohn (2008, p. 92), “[...] atuam segundo critérios vagos de um humanismo liberal, que visa ajudar o próximo, de preferência via trabalho voluntário, criando instituições bastante atreladas às políticas públicas [...]". Nesse sentido, Montaño (2001) relembra o efeito ideológico do "ócio criativo": o tempo livre vira mote para o desenvolvimento de atividades voluntárias em prol da comunidade em que vive o trabalhador e, assim, a problemática social (ambiental e educacional, por exemplo) torna-se mais amena.

0 que incomoda é que não há transparência e não há publicização do cotidiano das ONGs. Todavia, elas ganham legitimidade a partir do momento em que a sociedade aponta para a necessidade da atuação estratégica - estratégica porque é uma "manobra de guerra" que dá emprego (Arantes, 2004b) - dessas entidades em áreasproblema, no lugar da inoperância do Estado (Gohn, 2008). Para além disso, ainda conforme Gohn (2008), os escassos estudos a respeito das ONGs são feitos de dentro delas e por seus intelectuais, embora muitas estejam dentro das universidades. Vale ressaltar: '[...] dificilmente um 'ongueiro' ou 'ex-ongueiro' se liberta dos condicionamentos da forma de ver e agir do mundo das ONGs" (Gohn, 2008, p. 101).

$\mathrm{E}$, para não terminar o debate, aqui apenas introduzido, rascunha-se a intersecção crise socioambiental / educação ambiental / Organizações Não Governamentais. 
Intui-se evidenciar a necessidade indiscutível de se estudar o tema, pois a ameaça à vida justa está posta e o direito ao ambiente saudável está em perigo, enquanto, no chão da escola, a educação para a transformação definha. Para Loureiro,

[...] naquilo que se refere à atividade educativa, quando pensamos em mudar a realidade em busca de novos patamares societários na natureza, não bastam a ação comunicativa, a razoabilidade argumentativa e a alteridade. Esses valores e o diálogo devem ser construídos na prática pedagógica vinculados à compreensão crítica dos interesses, necessidades e conflitos estabelecidos em dada organização social, no caso, uma organização capitalista, portanto, desigual no uso e apropriação da base vital e na distribuição do que é socialmente criado, produzido. (Loureiro, 2009, p. 6).

\section{Para continuar o debate}

Na conclusão, a dúvida. No fim, o retorno. E, nessa dialetizante perspectiva, retorna-se ao texto inicial. Brecht (2000) narra o queimar de uma árvore para provocar reflexão sobre o que causa incômodo, o que causa estranheza. Assim, faz pensar atitudes que revertam uma situação aparentemente incontornável.

A crise socioambiental que se vivencia hoje, trazida à luz pela metáfora da árvore, tem sido tomada também como natural, uma vez inserida no modo de produção capitalista que a desenvolveu e que, ademais, é dado como infindável. Tais concepções, vinculadas às percepções individuais/coletivas, parecem intangíveis e fechadas aos reducionismos em que os sujeitos se assentaram. Nesse contexto, dentre as estratégias mais cruéis do modo de produção material da vida deste século, para a sua conservação, surge o que é menos perceptível aos olhos desatentos. E é também no campo educacional que se têm firmado e reproduzido, numa nova pedagogia da hegemonia, das boas intenções à ilegalidade, novos mecanismos de articulação numa perspectiva eternizante do capital.

A educação ambiental especificamente, esperançosa da promoção de sociedades mais justas e ambientalmente equilibradas, entrou também nesse jogo laté porque não há nada fora dele), não obstante haja nela uma forte tendência crítica e de luta pela transformação. Não é de assombrar que instituições de cunho duvidoso, como é o caso de muitas Organizações Não Governamentais ambientalistas, entrem nesse campo de disputa e contribuam com vertentes conservadoras de educação ambiental.

Entretanto, acreditar que um sujeito revolucionário haverá de se organizar/ reorganizar é das mais nobres crenças numa época em que crença, fé, espiritualidade, sonho, etc., são comercializados. E, mais uma vez, faz-se referência ao contraditório, ao paradoxal, ao malandro mundo do capital. Logo, ficam aqui alguns questionamentos, 
algumas dúvidas, algumas sumárias observações, a fim de que se contribua com um debate que, tal qual o cerne de seu tema, parece intransponível.

Brecht, em uma de suas mais célebres criações, e mais uma vez, finaliza este ensaio - não o debate -, oferecendo asas aos que desistiram de acreditar, neste contexto, em outra sociedade:

\author{
[...] Até o mínimo gesto, simples na aparência, \\ Olhem desconfiados! Perguntem \\ Se é necessário, a começar do mais comum! \\ E, por favor, não achem natural \\ 0 que acontece e torna a acontecer \\ Não se deve dizer que é natural! \\ Numa época de confusão e sangue, \\ Desordem ordenada, arbítrio de propósito, \\ Humanidade desumanizada \\ Para que imutável não se considere \\ Nada. (Brecht, 1990, p. 132).
}

\title{
Referências bibliográficas
}

ARANTES, Paulo. A fratura brasileira do mundo. In: Zero à esquerda. São Paulo: Conrad Livros, 2004a, p. 25-78.

. Esquerda e direita no espelho das ONGs. In: Zero à esquerda. São Paulo: Conrad Livros, 2004b, p. 165-190.

ARRUDA, Marcos. ONGs e o Banco Mundial: é possível colaborar criticamente? In: TOMMASI, Lívia; WARDE, Miriam Jorge; HADDAD, Sérgio. (Orgs.). O Banco Mundial e as políticas educacionais. São Paulo: Cortez, 1996, p. 75-123.

BRASIL. Decreto-lei n. 9795, de 27 de abril de 1999. Dispõe sobre a Educação Ambiental e institui a Política Nacional de Educação Ambiental e dá outras providências. Diário Oficial da República Federativa do Brasil. Brasília, 1999.

BRECHT, Bertold. Poemas 1913-1956. Seleção e tradução de Paulo César de Souza. São Paulo: Editora 34, 2000.

. A exceção e a regra. Tradução de Geir Campos. In: . Teatro completo em 12 volumes. Rio de Janeiro: Paz e Terra, 1990. (Coleção Teatro, v. 4)

CAMBA, Salete Valesan. ONGs e escolas públicas: uma relação em construção. São Paulo: Editora e Livraria Paulo Freire, 2009.

CHESNAIS, François. As origens da crise econômica e da crise ecológica. 0 olho na história, Salvador, n. 13, dez. 2009. Não paginado. Disponível em: <http://oolhodahistoria.org/n13/ artigos/chesnais.pdf>. Acesso em: 15 jul. 2010. 
COUTINHO, Joana. Aparecida. Organizações Não-Governamentais: o que se oculta no "não"? Revista Espaço Acadêmico, ano III, n. 24, mai. 2003. Não paginado. Disponível em: <www.espacoacademico.com.br/024/24ccoutinho.htm>. Acesso em: 16 ago. 2010.

DAGNINO, Eveline. Políticas culturais, democracia e o projeto neoliberal. Revista Rio de Janeiro, Rio de Janeiro, n. 15, p. 45-65, jan./abr. 2005.

FERNANDES, Florestan. Em busca do socialismo: últimos escritos e outros textos. São Paulo: Xamã, 1995.

GOHN, Maria da Glória. O protagonismo da sociedade civil: movimentos sociais, ONGs e redes solidárias. 2. ed. São Paulo: Cortez, 2008.

GUIMARÃES, Mauro. A formação de educadores ambientais. Campinas: Papirus, 2004.

LAYRARGUES, Philippe Pomier. 0 cinismo da reciclagem: o significado ideológico da reciclagem da lata de alumínio e suas implicações para a educação ambiental. In: LOUREIRO, Carlos Frederico Bernardo; LAYRARGUES, Philippe Pomier; CASTRO, Ronaldo Souza de (Orgs.). Educação ambiental: repensando o espaço da cidadania. 3. ed. São Paulo: Cortez, 2005, p. 179-220.

LIMA, Kátia Regina de Souza; MARTINS, André Silva. Pressupostos, princípios e estratégias. In: NEVES, Lúcia M. Wanderley (Org.). A nova pedagogia da hegemonia: estratégias do capital para educar o consenso. São Paulo: Xamã, 2005, p. 43-68.

LOUREIRO, Carlos Frederico Bernardo. Crítica ao fetiche da individualidade e aos dualismos na educação ambiental. In: LOUREIRO, Carlos Frederico Bernardo (Org.). Educação ambiental, gestão pública, movimentos sociais e formação humana. São Carlos: RiMa Editora, 2009, p. 1-14.

Educação ambiental e movimentos sociais na construção da cidadania ecológica e planetária. In: LOUREIRO, Carlos Frederico Bernardo; LAYRARGUES, Philippe Pomier; CASTRO, Ronaldo Souza de (Orgs.). Educação ambiental: repensando o espaço da cidadania. 3. ed. São Paulo: Cortez, 2005, p. 69-98.

LÖWY, Michel. Ideologias e ciência social: elementos para uma análise marxista. 4. Ed. São Paulo: Cortez, 1988.

MELO, Adriana Almeida Sales de. Os organismos internacionais na condução de um novo bloco histórico. In: NEVES, Lúcia Maria Wanderley (Org.). A nova pedagogia da hegemonia: estratégias do capital para educar o consenso. São Paulo: Xamã, 2005, p. 69-82.

MELO, Liana. Índios do Pará terão crédito de carbono. O Globo, 2009. Não Paginado. Disponível em: <http://oglobo.globo.com/economia/mat/2009/06/06/indigenas-do-para-vao-assinarprimeiro-contrato-de-credito-de-carbono-para-preservar-florestas-756229768.asp >. Acesso em: 10 set. 2010.

MENEGAT, Marildo. O olho da barbárie. São Paulo: Expressão Popular, 2006.

MÈSZAROS, Istvan. Para além do capital. São Paulo: Boitempo Editorial, 2002.

MONTAÑO, Carlos. Política social e participação societária. Sociedade em debate, Pelotas, v. 14, n. 1, p. 37-46, jan./jun. 2008.

. 0 projeto neoliberal de resposta à "questão social" e a funcionalidade do "terceiro setor". Lutas Sociais, São Paulo, v. 8, p. 53-64, 2001.

OLIVEIRA, Francisco de. Política numa era de indeterminação: opacidade e reencantamento. 
In: OLIVEIRA, Francisco de; RIZEK, Cibele Saliba (Orgs.). A era da indeterminação. São Paulo: Boitempo, 2007, p. 15-45.

PAOLI, Maria Célia. 0 mundo do indistinto: sobre gestão, violência e política. In: OLIVEIRA, Francisco de; RIZEK, Cibele Saliba (Orgs.). A era da indeterminação. São Paulo: Boitempo, 2007, p. 221-156.

PETRAS, James. Neoliberalismo: América Latina, Estados Unidos e Europa. Blumenau: FURB, 1999.

PORTO, Marcelo Firpo; PACHECO, Tania. Conflitos e injustiça ambiental em saúde no Brasil. Tempus: Acta em Saúde Coletiva, Brasília, v. 4, n. 4, p. 26-37, 2009.

RODRIGUES, Jéssica do Nascimento. Das concepções prévias aos sentidos construídos na formação crítica do educador ambiental. 2010. 180 f. Dissertação (Mestrado em Educação) - Instituto de Educação/Instituto Multidisciplinar, Universidade Federal Rural do Rio de Janeiro, Seropédica/Nova Iguaçu, 2010.

SANTOS, Laymert Garcia dos. Brasil contemporâneo: estado de exceção? In: OLIVEIRA, Francisco de; RIZEK, Cibele Saliba (Orgs.). A era da indeterminação. São Paulo: Boitempo, 2007, p. 289-352.

TELLES, Vera da. Silva. Transitando na linha de sombra, tecendo as tramas da cidade (anotações inconclusas de uma pesquisa). In: OLIVEIRA, Francisco de; RIZEK, Cibele Saliba (Orgs.). A era da indeterminação. São Paulo: Boitempo, 2007, p. 195-218.

TINOCO, Dandara. 'Sei que vou ser assassinado, só não sei o dia', diz pescador ameaçado. O Globo, 2011. Não Paginado. Disponível em: <https://conteudoclippingmp.planejamento. gov.br/cadastros/noticias/2011/6/5/sei-que-vou-ser-assassinado-so-nao-sei-o-dia-dizpescador-ameacado>. Acesso em: 5 ago. 2011.

UEMA, Elisabeth Eriko. Pensando e praticando a educação no processo de gestão ambiental: controle social e participação no licenciamento. Brasília: IBAMA, 2006.

Recebido em novembro de 2011

Publicado em março de 2012

Jéssica do Nascimento Rodrigues, doutoranda em Educação pela Universidade Federal Fluminense. Mestre em Educação pela Universidade Federal Rural do Rio de Janeiro. Membro do Laboratório de Investigação em Educação, Ambiente e Sociedade (LIEAS/ UFRJ). E-mail: jessicarbs@gmail.com

Carlos Frederico Bernardo Loureiro, doutor em Serviço Social pela Universidade Federal do Rio de Janeiro. Professor do Programa de Pós-Graduação em Educação e do Programa de Pós-Graduação em Psicossociologia de Comunidades e Ecologia Social na UFRJ. Líder do Laboratório de Investigação em Educação, Ambiente e Sociedade (LIEAS/UFRJ) e bolsista de produtividade em pesquisa do CNPq. Publicação recente: Sustentabilidade e educação: um olhar da ecologia política. (São Paulo: Cortez, 2012). E-mail: floureirodopenlink.com.br 